\title{
The association between continual, year-round hunting and bellowing rate of bison bulls during the rut
}

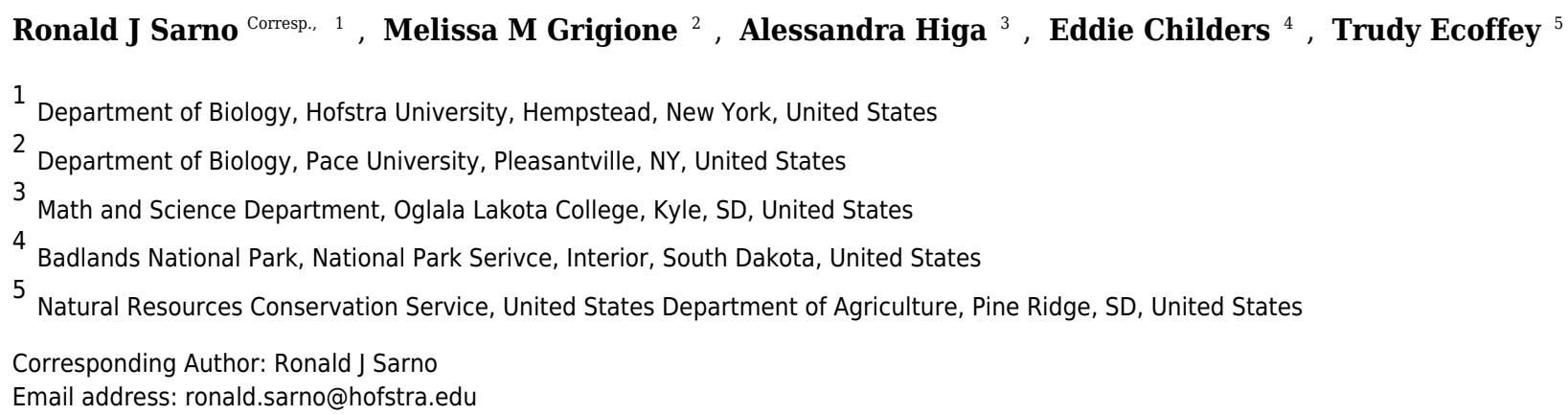

The impact of hunting (selective harvest, trophy hunting) on the demography of mammals is well documented. However, despite continual year-round hunting of bison in some populations, little is known about how the behavior of survivors may be altered. Therefore, in this initial study, we used focal-animal observations in adjacent populations of continually hunted and protected Plains bison (Bison bison bison) in western South Dakota, to examine the potential impact of hunting on bellowing rate- an important behavior that serves to intimidate rival bulls and potentially influences mate choice by females. In addition to hunting, we investigated how the number of attendant males, number of adult females, group size, and number of days from the start of rut influenced bellowing rate. Bulls bellowed an order of magnitude more often in the protected population than in the hunted populations, whereas bellowing rate was not significantly different in the hunted populations. Hunting was significantly and negatively associated with bellowing rate, while all other predictors were found to be positively associated with bellowing rate. Furthermore, the impact of hunting on bellowing rate became more pronounced (i.e., dampened bellowing rate more strongly) as the number of attendant males increased. Changes in bellowing behavior of bulls (and possibly mate choice by cows) can alter breeding opportunities. Therefore, our data suggest the need for studies with broaderscale geographical and temporal replication to determine the extent that continual yearround hunting has on bellowing rate of bison during the rut. If reduced bellowing is associated with human hunting on a larger scale, then wildlife managers may need to adjust hunting rate and duration, timing (season), and the time lag between hunting events in order to insure that bison are able to express their full repertoire of natural mating behaviors. 
1 The association between continual, year-round hunting and bellowing rate of

2

3

4

5 *RONALD J. SARNO, Department of Biology, Hofstra University, 130 Gittleson Hall,

$6 \quad$ Hempstead, NY 11549, USA

7

\section{bison bulls during the rut.}

RH: Sarno et al. • Hunting and reduced bison bellows

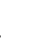

Email:ronald.sarno@hofstra.edu; Phone 516-463-4266; Fax 516-463-5122

MELISSA M. GRIGIONE, Department of Biology, Pace University, 861 Bedford Road,

Pleasantville, New York 10570

ALESSANDRA HIGA, Math and Science Department, Oglala Lakota College (OLC), 490 Piya

Wiconi Road, Kyle, SD 57752

EDDIE CHILDERS, Badlands National Park, 25216 Ben Reifel Road, PO Box 6, Interior, SD 57750

TRUDY ECOFFEY, USDA, Natural Resources Conservation Service, PO Box 2024, Pine Ridge, SD 57770

* Corresponding Author 
21 ABSTRACT The impact of hunting (selective harvest, trophy hunting) on the demography of

mammals is well documented. However, despite continual year-round hunting of bison in some populations, little is known about how the behavior of survivors may be altered. Therefore, in this initial study, we used focal-animal observations in adjacent populations of continually hunted and protected Plains bison (Bison bison bison) in western South Dakota, to examine the potential impact of hunting on bellowing rate- an important behavior that serves to intimidate rival bulls and potentially influences mate choice by females. In addition to hunting, we investigated how the number of attendant males, number of adult females, group size, and number of days from the start of rut influenced bellowing rate. Bulls bellowed an order of magnitude more often in the protected area than in hunted areas, whereas neither hunted population significantly differed in bellowing rate. Hunting was significantly and negatively associated with bellowing rate, while all other predictors were found to be positively associated with bellowing rate. Furthermore, the impact of hunting on bellowing rate became more pronounced (i.e., dampened bellowing rate more strongly) as the number of attendant males increased. Changes in bellowing behavior of bulls (and possibly mate choice by cows) can alter breeding opportunities. Therefore, our data suggest the need for studies with broader-scale geographical and temporal replication to determine the extent that continual year-round hunting has on bellowing rate of bison during the rut. If reduced bellowing is associated with human hunting on a larger scale, then wildlife managers may need to adjust hunting rate and duration, timing (season), and the time lag between hunting events in order to insure that bison are able to express their full repertoire of natural mating behaviors. 


\section{Introduction}

45 Humans have become a dominant, global evolutionary force (Palumbi 2001; Darimont et al.

46 2009). Our exploitation (hunting and fishing) of wild populations has induced rapid phenotypic

47 and life-history changes (Ciuti et al. 2012; Darimont et al. 2009) on decadal time scales

48 (Darimont et al. 2009; Coltman et al. 2003; Carlson et al. 2007). For example, in just 30 years

49 Coltman et al. (2003) observed significant declines in ram weight and horn length of bighorn

50 sheep (Ovis canadensis) due to unrestricted trophy hunting. Such rapid change can have

51 profound impacts on the evolution and conservation of exploited populations because of their

52 potential impact on population persistence (Yoshida et al. 2003; Fussman et al. 2007). While

53 much attention has focused on how human exploitation induces phenotypic and life-history

54 changes (Darimont et al. 2009; Hendry et al. 2008), there is little known about how hunting

55 influences reproductive behavior of survivors in the numerous species of ungulates that are

56 hunted globally (Cromsigt et al. 2013; Ripple et al. 2015).

57

58

59

60

61

62

63

64

65

\section{Management of ungulates}

Many ecosystems are experiencing real [cervids in US, Europe, and Japan;] (Côté et al. 2005), or locally perceived [Asia, Tibetan wild ass (Equus kiang)(Schaller 1998); South

America, guanaco (Lama guanicoe) and vicuña (Vicugna vicugna)] (Baldi et al. 2010; RJ Sarno pers obs), increases in ungulate densities, and many of these systems require extensive management. Human hunting, either prescribed or poaching, is considered a form of predation risk that can divert time/energy from fitness-enhancing activities such as feeding, parental care, or mating (Lima and Dill 1990; Lima 1998). In fact, ungulates can show stronger behavioral responses to human hunting than to predation risk by large carnivores (Proffitt et al. 2009; Ciuti 
66

67

68

et al 2012). Other potential fitness-decreasing activities associated with hunting include increased movement and frequency of changing groups in elk (Cervus elaphus; Cleveland et al. 2012; Proffitt et al. 2009), increased vigilance and movement in red deer (Cervus elaphus; Jayakody et al. 2008), and more frequent changes in habitat and space use in red deer, roe deer (Cervus capreolus), and European bison (Bison bonasus; Theuerkauf et al. 2008). Flight initiation distance has also been documented to significantly increase in several hunted populations of artiodactyls (Stankowich 2008).

Despite the ubiquity of harvesting ungulates for food and trophies (Proaktor et al. 2007; Ripple et al. 2015), an understanding of the population-wide effects of hunting on the behavior of survivors remains fragmentary. Events commonly associated with hunting such as firearm discharge, observing downed conspecifics, pursuit by motor vehicles, and/or the presence of humans in close proximity for extended periods of time may produce behavioral changes in survivors. Associations with any of these possibly traumatic events can lead to sensitization to human presence, which in turn, may increase vigilance or stress levels, or suppress functional behaviors such as grooming, feeding, or vocalizations (MacArthur et al. 1982). To our knowledge, the potential impact of hunting on behaviors explicitly tied to male reproductive ecology (e.g., mate advertisement, threat displays to potential competitors, fighting) has not been investigated.

\section{Ecology and management of bison}

This gap in the literature is particularly important because population-level responses to human activities will be crucial to successful restoration and long-term conservation of the iconic plains bison (Bison bison bison). Initial observations indicated that bulls in hunted populations were less vocal than those in a protected population (R.J. Sarno, personal observation). 
89 Therefore, we hypothesized that in a risky environment (i.e., human hunting), the best strategy

90 for reproductively-active bulls may be to dampen vocalizations, because bellowing bulls may be

91 targeted by hunters' sooner than other animals. Bison form large aggregations during the

92 breeding season (rut) when mature bulls join mixed-sex and age groups. Males exhibit a linear

93 dominance hierarchy, with older, larger bulls dominant to smaller, younger bulls (Komers et al.

94 1994; Roden et al. 2005). Dominant males temporarily consort with cows prior to or during

95 estrus and attempt to keep all other bulls away by engaging in vocalizations, threat displays, and

96 fights.

97 The most conspicuous and frequent vocalizations made by bison bulls during the rut are

bellows. Bellows function to intimidate rival males (Berger and Cunningham 1991;1994), while

99 bellow amplitude has been linked to male body condition (Wyman et al. 2008). Importantly,

100 amplitude and bellow quality are directly tied to mating success (Wyman et al. 2008).

101 Vocalizations by males of different species also provide information on female reproductive

102 status (Semple and McComb 2000), influence female mate choice (McComb 1991; Reby et al.

103 2010), accelerate estrus (McComb 1987), and deter rival males (Clutton-Brock and Albon 1979;

104 Bowyer and Kitchen 1987) and predators (Tilson and Norton 1981). Therefore, any changes in

105 bellowing behavior due to perceived predation risk (Lima and Dill 1990; Lima 1998) could have

106 profound consequences for bison reproductive ecology (Berger and Cunningham 1994; Wyman

107 et al. 2008).

108 Given the importance of bellows during the mating period, and the use of hunting as a

109 management tool, it is essential that we understand the degree to which hunting, or associated

110 events, influence mating behavior of survivors. Therefore, our primary objective was to use

111 focal-animal observations to compare bellowing frequency of male bison in three populations 
112 during the rut (1 protected and 2 hunted) in western South Dakota. In addition, we assessed the

113 influence of possible predictor variables on the frequency of bellowing rate. We hypothesized

114 that if continual, year-round hunting of bison alters bellowing rate, then bulls in hunted

115 populations will bellow less frequently than bulls in protected populations during the rut.

\section{METHODS}

\section{Study Area}

118 Badlands National Park (protected population)

119 Badlands National Park $\left(43.8554^{\circ} \mathrm{N}, 102.3397^{\circ} \mathrm{W} ; 194.3 \mathrm{~km}^{2}\right)$ includes a population of

120 bison not subject to annual hunting mortality and is located approximately $113 \mathrm{~km}$ east of Rapid

121 City, and $13 \mathrm{~km}$ south of Wall, South Dakota, U.S.A. We conducted behavioral observations in

122 the Sage Creek Wilderness Area, located in the Northern Unit of the park. The study area varies

123 from $800-1100 \mathrm{~m}$ in altitude and the landscape is characterized as relatively flat, open grassland

124 with intermittent rolling hills, draws, mesas, and buttes (National Park Service 2003). The

125 dominant grassland species is western wheatgrass (Agropyron smithin). Wheatgrass/green

126 needlegrass (Nasella viridula) associations occur on small hills, slopes, and buttes. Rocky

127 Mountain juniper forests (Juniperus scopulorum) are the most common forest type and dominate

128 the drier slopes, butte edges, and upper draws of the study area (National Park Service 2003).

129 Badlands National Park is characterized by hot, dry summers, and cold, dry winters.

130 Weather is variable, and temperature extremes range between $-40^{\circ}-47^{\circ} \mathrm{C}$. Average yearly

131 precipitation is nearly $40 \mathrm{~cm}$, and most occurs between April and September. Average daily

132 maximum temperature during the warmest month (July) is $33^{\circ} \mathrm{C}$ (BNP National Weather Service 133 record of river and climatological observations). 


\section{Pine Ridge Reservation (two hunted populations)}

The Pine Ridge Indian Reservation is a reservation of the Oglala Sioux in South Dakota, USA, and was established in 1889 in the southwest corner of the state. Pine Ridge Reservation $\left(43.2731^{\circ} \mathrm{N}, 102.7445^{\circ} \mathrm{W}\right)$ bison pastures (hunted populations) are located in the central and southwestern portion of the reservation in Bennett County, South Dakota. Pastures range in elevation from $762-1219 \mathrm{~m}$. Annual precipitation varies from $33-48 \mathrm{~cm}$, and summer/winter temperatures mirror those of Badlands National Park (Graham and Gingerich 2013). Bison on Pine Ridge Reservation are hunted throughout the year.

Yellow Bear Pasture $\left(39 \mathrm{~km}^{2}\right)$ is the site of one of the hunted bison populations and is located approximately $30 \mathrm{~km}$ southeast of Kyle, South Dakota $\left(43.4250^{\circ} \mathrm{N}, 102.1765^{\circ} \mathrm{W}\right)$ and $85 \mathrm{~km}$ southeast of Badlands National Park. The landscape is open and undulating and dominated by cheat grass (Bromus tectorum), western wheatgrass, buffalograss (Bouteloua dactyloides), and little bluestem (Schizachyrium scoparium). Canyons also are present, and canyon ridge-tops are dominated by ponderosa pine (Pinus ponderosa). Other common tree species include Rocky Mountain juniper, green ash (Fraxinus pennsylvanica), and eastern cottonwood (Populus deltoides; Graham and Gingerich 2013).

Slim Buttes Pasture $\left(49.7 \mathrm{~km}^{2}\right)$ contains the second hunted bison population on Pine Ridge and is located approximately $20 \mathrm{~km}$ northwest of Pine Ridge, South Dakota (43.0255 $\mathrm{N}$, $102.5563^{\circ} \mathrm{W}$ ) and $155 \mathrm{~km}$ southwest of Badlands National Park. The same grasses that are found in Yellow Bear Pasture also are present in Slim Buttes. Eastern cottonwood and Rocky Mountain juniper are the dominant tree species (Graham and Gingerich 2013). 


\section{Hunting events}

159

160

161

162

163

164

165

166

167

168

169

170

171

172

173

174

175

176

177

178

179

180

Hunts were conducted year-round in Slim Buttes Pasture and Yellow Bear Pasture with .270 or .25-06 caliber centrefire rifles. In each bison pasture there were 3 hunting events per month (T. Ecoffey, United States Department of Agriculture, personal communication). The number of animals taken and the duration of hunts varied. During ceremonial hunts, shooters usually approached bison in motor vehicles (2-3 vehicles with 4-5 people total) to within 50$100 \mathrm{~m}$. Non-lactating cows and 2-3 year-old bulls were usually selected during hunts, though older bulls (greater than 5 years old) were also removed. During these short ceremonial hunts only one or two bison were taken, and most hunts lasted approximately two hours (Graham and Gingerich 2013).

During non-ceremonial, commercial hunts, up to 8 animals were removed in 6 hours. Here, a mobile abattoir was utilized, whereby animals were first driven into a holding pasture where two people approached bison to within 25-50 m before discharging their rifles. One animal at a time was downed and carcasses were removed from the pasture and processed at which time shooters re-entered the pasture and repeated the procedure until eight bison had been removed. Remaining animals were then re-released into the pasture (T. Ecoffey, United States Department of Agriculture, personal communication).

\section{Data Collection}

We defined bellowing rate as the total number of distinct bellows by focal bulls that were recorded by the observer during 15-minute observations. Bellows were quantified using a stopwatch and a manual hand counter. From a stationary vehicle, we conducted 245, 15-min focal observations (Altmann 1974) of mature bulls between dawn and dusk from 1 July to 13 August 2013 using Vortex binoculars and Leica spotting scopes. We conducted 62 observations 
181 among 17 groups in Badlands National Park, 101 observations among 34 groups in Yellow Bear

182 pasture, and 79 observations among 25 groups in Slim Buttes pasture. Mature bulls were defined 183 as bulls greater than four years old (when marked) or those accompanying a cow during the rut

184 when not marked. Group size and composition (i.e., number of attendant males [mature bulls], 185 adult females, juvenile males/females) was defined by the number of animals within $50 \mathrm{~m}$ of the 186 focal bull. All mature bulls, whether bellowing or not, that were accompanying a cow were 187 considered to be participating in the rut, and therefore could be included as focal animals. We 188 minimized pseudo-replication by identifying animals based on tag numbers and natural 189 markings. When bulls could not be distinguished by natural markings or ear tags, we visited different groups for each observation and focal individuals were selected haphazardly. We observed bison as close as we could safely approach them throughout the day $(50 \mathrm{~m})$, while attempting to avoid oversampling during any particular time of day. Bison did not appear to be bothered by the presence of stationary vehicles in any of the sites as cows and calves routinely passed by parked vehicles within $5 \mathrm{~m}$. Bulls also passed by parked vehicles within 3-5 $\mathrm{m}$ while bellowing and fighting other bulls as well as accompanying cows. Therefore, we do not believe that the data were influenced by the presence of observers in motor vehicles. In order to standardize the time period that we observed the rut among pastures, we limited our observations to three weeks after the date of initially observing bellows by bulls in each study site. For example, bellows were first recorded on 6 July in Badlands National Park, 16 July in Yellow Bear pasture, and 17 July in Slim Buttes pasture. Therefore, data were collected in Badlands National Park until 2 August. In Yellow Bear and Slim Buttes pastures data were collected until 9 and 10 August, respectively. Consequently, observation day (described below in the analysis) 
203 indicated the progress of the rut (i.e., the number of days that had elapsed after the day that the 204 first bellow was observed).

205 We characterized adult sex ratios and numbers of bison in each population (Badlands

206 National Park: Population Size $=1,204$, Density $=6.2 / \mathrm{km}^{2}$, Adult Male:Female Ratio $=1: 10$;

207 Yellow Bear Pasture: Population Size $=464$, Density $=11.9$, Adult Male:Female Ratio = 1:22;

208 Slim Buttes Pasture: Population Size $=184$, Density $=3.7$, Adult Male:Female Ratio $=1: 15$ )

209 utilizing data collected by Badlands National Park and Oglala Sioux Parks and Recreation

210 Authority (OSPRA) personnel during fall roundups. Each of the three study sites were

211 considered independent as all pastures were surrounded by fences.

212 Ethics Statement

213 Sensitization can be considered an important indirect effect of hunting; therefore, we

214 observed animals only in areas where bison were subjected to regular human visitation. Data

215 collection did not involve restricted habitat or interference with other species, and was in

216 compliance with institutional (Hofstra University IACUC \# 13/14-5) and national guidelines for

217 ethical conduct in the care and use of nonhuman animals in research. We obtained permission to

218 conduct fieldwork in Badlands National Park (Permit \#: BADL-2013-SCI-0009) and Pine Ridge

219 Reservation.

220 Data analysis

Initially, a series of descriptive statistics of the data were generated. Due to high skew

222 (3.7) and kurtosis (22.2) of bellowing rate, a series of attempted transformations, including

223 square root, log, and numerous others, along with the application of the Johnson family of

224 transformations were run. However, all failed to substantially improve the normality of the data.

225 Therefore, we utilized non-parametric bivariate statistics along with Poisson regression, to 
226 appropriately model the distribution of bellowing rate. Additionally, scatterplots of bellowing

227 rate and the continuous predictors (number of attendant males, number of adult females, group

228 size, observation day, and hunting) were investigated in order to ensure linearity as well as the

229 absence of outliers. Linearity was indicated in all cases, with a single extreme outlier found with

230 respect to bellowing rate. However, the removal of this outlier failed to substantially change the

231 results of all analyses conducted; therefore, no cases were removed from the analyses.

Spearman's correlations were initially performed in order to determine the strength,

233

234

235

236

237

238

239

240

241

242

243

244

245

246

247

248

significance, and direction of the relationship between bellowing rate and the predictor variables.

An $|r|$ greater than 0.75 was used as the threshold for indicating serious multicollinearity (Mun 2008). We used a Mann-Whitney $U$ test to compare bellowing rate between the two hunted and one protected population, while a Kruskal-Wallis ANOVA with multiple comparisons was used to assess any differences in bellowing rate among the three populations. Finally, two Poisson regressions were conducted in order to determine the extent to which the predictor variables impacted bellowing rate. These multivariate regressions served to determine the impact of each predictor on the outcome of bellowing rate, while holding all other predictors in the model constant. The initial model only included main effects. The second model included an interaction between the number of attendant males and hunting. All analyses were performed using Stata 13.1.

\section{RESULTS}

The Kruskal-Wallis ANOVA comparing the three associated medians was statistically significant $\left(\chi^{2}(2)=81.4, p<.001\right)$. Median bellowing rate was an order of magnitude higher in the non-hunted Badlands National Park population $\left(\mathrm{Med}=39,25^{\text {th }}\right.$ and $75^{\text {th }}$ quartiles $=[4,80]$, Range $=76)$ than in the hunted Pine Ridge populations $\left(\mathrm{Med}=0,25^{\text {th }}\right.$ and $75^{\text {th }}$ quartiles $=[0,0]$, 
249 Range $=0$ ). While the median difference between the protected and hunted populations was

250 significant, median bellowing rate in Yellow Bear $\left(\mathrm{Med}=0,25^{\text {th }}\right.$ and $75^{\text {th }}$ quartiles $=[0,0]$,

251 Range $=0)$, and Slim Buttes pastures $\left(\mathrm{Med}=0,25^{\text {th }}\right.$ and $75^{\text {th }}$ quartiles $=[0,0]$, Range $\left.=0\right)$ on

252 Pine Ridge was similar $(\mathrm{p}>0.05)$.

253

All Spearman's correlations between bellowing rate and the predictor variables were

254

255

256

257

258

259

260

261

262

263

264

265

266

267

268

269

270

271 statistically significant except those between bellowing rate and the number of attendant males and adult females (Table 1). Group size was positively correlated with bellowing rate, while observation day and hunting were negatively correlated with bellowing rate. Correlations between the number of attendant males and the remaining predictor variables (group size, observation day, hunting and number of adult females) were also significant and positive. Group size was significantly and positively correlated with the number of adult females, yet group size exhibited a significant, negative correlation with observation day and hunting.

The results of the first Poisson regression (Table 2) indicate that all predictor variables significantly influenced bellowing rate. Number of attendant males, number of adult females, group size, and observation day (i.e., progress of the rut) positively impacted bellowing rate, while hunting suppressed bellowing rate. For example, the incidence rate ratios (IRR) indicate that average bellowing rate in the hunted populations was about $5 \%$ that of the protected population. In contrast, average bellowing rate was predicted to increase by $5 \%$ with the addition of each attendant male. The variance inflation factors, taken from an identically specified linear regression model, indicated no substantial multicollinearity using the common cutoff value of 5 (Oyana and Margai 2015).

The second Poisson regression analysis (Table 3) incorporated the interaction between hunting and number of attendant males. All main effects were again statistically significant as 
272 was the interaction between hunting and the number of attendant males. The positive direction of

273 the hunting*number of attendant males interaction indicates that bellowing rate increases with

274 number of attendant males to a greater extent in the protected population than in the hunted

275 populations. Dividing the data into observations above or below the mean number of attendant

276 males $(\bar{x}=4.3)$ revealed a substantial difference in median bellowing rate of bulls from the

277 protected population vs the hunted populations. For example, when the number of attendant

278 males was above 4.3, bulls in the hunted populations exhibited nearly 113 fewer bellows/15 min

279 (14 times less) than bulls in the protected population (Hunting: $M=8.6, S D=19.9$; No hunting:

$280 M=121.5, S D=117.1)$. When the number of attendant males was below 4.3 , bulls in the hunted

281 populations exhibit about 44 fewer bellows/15 min (29 times less) than bulls in the protected

282 population (Hunting: $\bar{x}=1.6, S D=9.3$; No hunting: $\bar{x}=46.0, S D=48.9$ ) (Fig. 1 ). No

283 substantial multicollinearity was indicated, though this was reduced substantially by first

284 standardizing the main effects associated with the interaction effect and using these standardized

285 measures in the calculation of the interaction. Both Poisson regression models were statistically

286 significant (p less than 0.001). The $R$-squared of both models was above 0.50 .

\section{Discussion}

Bulls in the hunted populations on Pine Ridge Reservation bellowed an order of magnitude less frequently than bulls in the protected Badlands National Park population; yet

290 bellowing rates between the hunted populations on Pine Ridge were not statistically different.

291 Hunting had a large negative effect on bellowing rate and was the only variable to do so.

292 It is plausible that the consistent number (3) of hunting events/month on Pine Ridge, combined with pursuit by - and/or forced close proximity to - motor vehicles and humans for 12 to 18

294 hours/month, may have impacted bellowing behavior. Because bison are generally found in the 
295 open, bellowing bulls may be targeted by hunters' sooner than non-bellowing bulls of equal size

296 and age class. Therefore, the best strategy in a risky environment in which there is human

297 hunting may be to dampened bellowing rate. Since there are no natural predators in any of these

298 populations that are a major threat to bison we can rule out the possibility that decreased

299 bellowing is a response to natural predation.

300 Approximately $40 \%$ of cows 3.5 years and older in Yellow Bear pasture produced calves 301 on a yearly basis (OLC Bison Management Plan 2013), while birth rate of similar-aged cows in 302 Badlands National Park was 90\% (E.Childers, Badlands National Park, pers. comm). While we 303 do not know the reason for this disparity, it is a possible and disconcerting demographic impact 304 of continual, year-round hunting. Pregnancy rates, however, will also be impacted by the estrus 305 state of cows. Pregnancy rates will also be impacted by the estrus state of cows, and there is 306 some concern that copper deficiencies in the diet of bison on Pine Ridge may be impacting 307 reproduction (Corah and Ives 1991, T Ecoffey and C Kelling unpublished data). Therefore, fewer 308 females entering estrus would likely have a negative impact on overall bellowing by bulls,

309 because bulls bellow most frequently when in the presence of estrus cows (Berger and 310 Cunningham 1994). We consider three additional factors that could influence bellowing rate. One, if density were important we would expect the highest bellowing rates to occur (all else being equal) at the 313 highest density, because potential rivals would be physically closer to one another. Bison density 314 in Yellow Bear pasture on Pine Ridge was nearly 2 times higher than that in protected Badlands 315 National Park, yet median bellowing rate of bison in Badlands was an order of magnitude higher 316 than bison in Yellow Bear Pasture. While bison density in Slim Buttes pasture on Pine Ridge 317 was 3.2 times lower than that in Yellow pasture, median bellowing rate of bulls in both 
318 populations was equal. Thus, the influence of density on bellowing rate is not well supported.

319 Two, the operational sex ratio (OSR) - the ratio of reproductively available adult females to

320 adult males - could conceivably influence bellowing rate due to the number of males vying for

321 females. As the operational sex ratio approaches unity (i.e., ratio of males/females approaches

322 1), we predict increasing bellowing rate due to increasing mate competition among bulls. The

323 operational sex ratio in Badlands National Park (1:9.8) was the closest to unity and bulls in this

324 population bellowed an order of magnitude greater than bulls in either of the Pine Ridge

325 populations. The operational sex ratio in Yellow Bear (1:22) pasture, however, was nearly 1.5

326 times higher than that in Slim Buttes (1:15.5), yet median bellowing rate in Slim Buttes and

327 Yellow Bear was equal. Thus, the impact of the operational sex ratio on bellowing rate in our

328 study is equivocal and deserves more attention in any future studies. Third, Berger and

329 Cunningham (1994) reported that the most important single factor influencing bellow rate was

330 copulatory status of bulls. After males copulated bellow rate dropped to an average of $16 \%$ of

331 pre-copulatory bellow rate. Because the Badlands National Park population $(\mathrm{n}=1205)$ was about

332 2.5 times larger than Yellow Bear $(n=448)$ and Slim Buttes $(n=463)$, it is possible that the

333 number of males that had not copulated and/or new males entering the rut was higher in

334 Badlands than on Pine Ridge, which would have tended to maintain the bellowing rate of bulls at

335 elevated levels in Badlands National Park compared to the hunted populations. Therefore,

336 population size may also influence bellowing rates of bulls during the reproductive period.

337 Perceived predation risk (Frid and Dill 2002) and disturbance (Gutzwiller et al. 1994)

338 diverts time and energy from mating displays in a number of species. Male Tungara frogs

339 (Engystomops pustulosus) stifled mating calls and sometimes abandoned mate advertisement in

340 response to perceived predation (Ryan 1985). Male Great snipes (Gallinago media) abandoned 
341 leks when disturbed or perceived risk to predation (Fiske and Kålås 1995). Among ungulates,

342 overall reproductive success of mule deer (Odocoileus hemionus) and caribou (Rangifer

343 tarandus) decreased when they were disturbed by ATV's and low-flying aircraft (Yarmoloy et

344 al. 1988; Harrington and Veitch 1992).

345 All remaining explanatory variables predicted increased bellowing rate. The addition of

346 each attendant male predicted an increase in bellowing rate by approximately $5 \%$. Berger and

347 Cunningham (1994) also reported a positive relationship between the number of attendant males

348 and bellowing rate. Although bellowing rate increased as the number of attendant males

349 increased, it did not occur with equal magnitude in the hunted (Pine Ridge) populations vs the

350 protected (Badlands National Park) population. When there were greater than 4.3 attendant males

351 (mean number of attendant males/group), bellowing rate by bulls in the hunted populations was

35214 times less than that of bulls in the non-hunted population. When there were less than 4.3

353 attendant males, bellowing rate by bulls in the hunted populations increased less by a factor of 29

354 compared with bulls in the non-hunted population. Bulls in the two hunted populations clearly

355 exhibited dampened bellowing rate, and the effect was more pronounced when there were few

356 attendant males.

357 The passage of each observation day was predicted to increase bellowing rate by $5.5 \%$.

358 We observed the initial three weeks of the rut, and, as a result, infer that cows continually

359 entered into estrus as the rut proceeded because the estrus state of cows influenced bellowing

360 rate of bulls (and the majority of copulations in the Badlands ecosystem occurred in July (Berger

361 and Cunningham 1994).Group size and the number of adult females in groups also positively

362 influenced bellowing rates, but to a much lesser extent, and their impact can be considered

363 negligible due to low IRR ratios in the regression analyses (Tables 2 and 3). 
364

365

366

367

368

369

370

371

372

373

374

375

376

377

378

379

380

381

382

383

384

385

386

\section{Implications for Conservation}

Human hunting can influence reproductive behavior of ungulates by skewing the sex

ratio and/or by removing certain individuals from a population (Bonenfant et al. 2004; Mysterud et al. 2003). Such changes can profoundly impact mating dynamics (Mysterud et al. 2002).

Consequently, knowledge of how and why individuals may vary in their reproductive behavior under specific regimes of human hunting will be important for effective management and conservation. It is possible that bison in Yellow Bear and Slim Buttes pastures on Pine Ridge have become sensitized to continual, year-round hunting. Therefore, our results should be of particular conservation relevance to bison because bellows function as an intrasexual display to deter rival males during the mating season (Berger and Cunningham 1994). Bellow amplitude and quality also have been directly associated with mating success (Wyman, 2006). Because vocalizations of male ungulates appear to impact mating success in a variety of ways, any changes in behavior could alter critical population-genetic parameters like effective population size (Wright 1931) and the capacity for populations to exhibit adaptive evolution. Because mate competition is an important evolutionary process, the IUCN Bison Specialist Group emphasizes the importance that bison express the full complement of natural mating behaviors (Gates et al. 2010) and stresses consideration of possible genetic consequences of all management actions, especially those for smaller herds; bellowing behavior is one such component that should be considered. One could argue, however, that bison still express natural mating behavior even if they bellow at diminished rates. It would be risky to assume, however, that decreases in bellowing would be linear among all animals. Differences in age and physical condition likely impact stamina, and therefore, the propensity of males to bellow. Human hunting may exacerbate these differences. 
fight rival males) can alter breeding opportunities - or possibly even effectively remove certain individuals from the breeding pool. Population-wide responses to hunting, like fear, are probably transmitted more quickly in social species (Cromsigt et al. 2013) like bison, where many individuals (on occasion) can witness conspecifics being downed by humans at close range. Therefore, we suggest that researchers and managers consider the potential that continual, yearround human hunting has to induce behavioral changes in survivors of exploited populations, especially those behaviors that are linked to mating success via mate advertisement and acquisition. In addition to replicating field observations in hunted vs. non-hunted populations, field experiments could also be conducted. For example, bellowing bulls from hunted and nonhunted populations could be recorded, bellows could be categorized, and playback calls could be presented to bulls and cows in order to measure their reaction. A more experimental approach would involve a BACI design (Green 1979), whereby one non-hunted population would be separated into two equal populations. Hunting could be introduced into one of the populations with the goal to observe any changes in bellowing behavior (including amplitude, rate, pitch, and timbre) of bulls during the rut. Ultimately, if reduced bellowing as a consequence of human

404 (season), and the time lag between hunting events in order to insure that bison are able to express 405 their full repertoire of natural mating behaviors.

\section{Acknowledgements}

407 We thank the administration at Oglala Lakota College (OLC), Oglala Sioux Parks and 
409 study (Permit \#: BADL-2013-SCI-0009). M. Thompson provided invaluable assistance in the 410 field and insights about bison on the Pine Ridge Reservation. 


\section{Literature Cited}

412 Altmann J (1974) Observational study of behavior: sampling methods. Behav 49:227-266.

413 Berger J, Cunningham C (1994) Bison: mating and conservation in small populations. Columbia $414 \quad$ University Press, New York.

415 Berger J, Cunningham C (1991) Bellows, copulations, and sexual selection in bison (Bison 416 bison). Behav Ecol 2:1-6.

417 Bonenfant C, Gaillard J-M., Klein F, Maillard D (2004) Variation in harem size of red deer (Cervus elaphus L.): the effects of adult sex ratio and age-structure. Journal of Zoology, 264:77-85.

420

421

422

423

424

425

426

427

428

429

430

431

432

Bowyer RT, Kitchen DW (1987) Sex and age-class differences in vocalizations of Roosevelt elk during rut. Amer Midl Nat 118:225-235.

Carlson SM, Edeline E, Asbjørn VL, Haugen TO, Winfield IJ, Fletcher JM, Ben JJ, Stenseth NC (2007) Four decades of opposing natural and human-induced artificial selection acting on Windermere pike (Esox lucius). Ecol Lett 10:512-521. doi:10.1111/j.14610248.2007.01046.x

Ciuti S, Muhly TB, Paton DG, McDevitt AD, Musiani M, Boyce MS (2012) Human selection of elk behavioral traits in a landscape of fear. Proc Roy Soc 279:4407-4416.

Cleveland SM, Hebblewhite M, Thompson M Henderson R (2012) Linking elk movement and resource selection to hunting pressure in a heterogeneous landscape. Wild Soc Bull 36:658-668.

Clutton-Brock TH, Albon SD (1979) The roaring of red deer and the evolution of honest advertisement. Behav 69:145-170. 
433 Coltman D, O'Donoghue W, Jorgenson P, Hogg J. T., Strobeck C, Festa-Bianchet M (2003)

$434 \quad$ Undesirable evolutionary consequences of trophy hunting. Nature 426:655-658.

435 Côté SD (2005) Extirpation of a Large black bear population by Introduced White-Tailed Deer.

$436 \quad$ Con Biol 19:1668-1671.

437 Cromsigt JPGM, Kuijper DPJ, Adam M, Beschta RL, Churski M, Eycott A, Kerley GIH,

438

439

440

441

442

443

444

445

446

447

448

449

450

451

452

453

Mysterud A, Schmidt K, West K (2013) Hunting for fear: innovating management of human-wildlife conflicts. Jour App Ecol 50:544-549 doi: 10.1111/1365-2664.12076.

Darimont CT, Carlson SM, Kinnison MT, Paquet PC, Reimchen TE, Wilmers CC (2009) Human predators outpace other agents of trait change in the wild. Proc Nat Acad Sci 106:952954.

Fiske P, Kålås JA (1995) Mate sampling and copulation behaviour of great snipe females. Anim Behav 49:209-219.

Frid A, Dill LM (2002) Human-caused disturbance stimuli as a form of predation risk. Con Ecol 6:11. http://www.consecol.org/vol6/iss1/art11/

Fussman GF, Loreau M, Abrams PA (2007) Eco-evolutionary dynamics of communities and ecosystems. Funct Ecol 21:465-477.

Gates CC, Freese CH, Gogan PJP, Kotzman (2010) American Bison: Status Survey and Conservation Guidelines 2010. International Union for Conservation of Nature and Natural Resources, Gland, Switzerland.

Graham T, Gingerich J (2013) Oglala Sioux Parks and Recreation Authority: Buffalo Expansion Feasibility Study, Bozeman, Montana. 
454 Green RH (1979) Sampling Design and Statistical Methods for Environmental Biologists. Wiley, $455 \quad$ Chichester

456 Gutzwiller KJ, Wiedemann RT, Clements KL, Anderson SH (1994) Effects of human intrusion 457 on song occurrence and singing consistency in subalpine birds. Auk 111:28-37.

458 Hendry AP, Farrugia TJ, Kinnison MT (2008) Human influences on rates of phenotypic change in wild animal populations. Mol Ecol 17:20-29. doi:10.1111/j.1365-294X.2007.03428.x

460

461

462

463

464

465

466

467

468

469

470

471

472

473

474

475

Harrington FH, Veitch AM (1992) Calving success of woodland caribou Exposed to Low-Level Jet Fighter Overflights. Arctic 45:213-218.

Jayakody S, Sibbald AM, Gordon IJ, Lambin X (2008) Red deer Cervus elephus vigilance behaviour differs with habitat and type of human disturbance. Wildl Biol 14:81-91.

Komers PE, Birgersson B, Ekvall K (1999) Timing of estrus in fallow deer is adjusted to the age of available mates. The American Naturalist. 153:431-436.

Komers P, Messier F, and Gates C (1994) Plasticity of reproductive behaviour in wood bison bulls: on risks and opportunities. Ethol Ecol \& Evol 6:481-495.

Lima SL (1998) Stress and decisoin making under the risk of predation: recent developments from behavioral reproductive, and ecological perspectives. Adv Study Behav 27:215-290.

Lima SL, and Dill LM (1990) Behavioural decisions made under the risk of predation. Can J Zool 27:619-640.

MacArthur RA, Geist V, Johnston RH (1982) Cardiac and behavioral responses of mountain sheep to human disturbance. J Wildl Manage 46:351-358.

McComb KE (1991) Female choice for high roaring rates in red deer, Cervus elaphus. Anim Behav 41:79-88. 
476 McComb K (1987) Roaring by red deer stags advances the date of oestrus in hinds. Nature $477 \quad 330: 648-649$

478 McComb K, Reby D (2005) Vocal communication networks in large terrestrial mammals. In:

$479 \quad$ McGregor Pm ed. Animal communication networks. Cambridge University Press 372$480 \quad 389$.

481

482

483

484

485

486

487

488

489

490

491

492

493

494

495

496

497

Mysterud A, Holand, Ø, Røed KH, Gjøstein H, Kumpula J, Nieminen M (2003) Effects of age, density and sex ratio on reproductive effort in male reindeer (Rangifer tarandus). Journal of Zoology 261:341-344.

Mysterud A, Coulson T, Stenseth NC (2002) The role of males in the dynamics of ungulate populations. J Anim Ecol 71:907-915.

Smith PG (2011) Behavior in ants. In: Jones HY, ed. Insect behavior in the Andes. Berlin: Springer Verlag 101-200.

Mun J (2008) Advanced analytical models: Over 800 models and 300 applications from the basel II accord to Wall Street and beyond. John Wiley \& Sons: Hoboken, New Jersey, USA.

National Park Service (2003) Badlands National Park: Pennington, Jackson and Shannon Counties, South Dakota. Integrated Weed Management Plan and Environmental Assessment. National Park Service, Interior, South Dakota, USA.

Oglala Sioux Parks and Recreation Authority. (2013) Buffalo Management Plan. Ranch Advisory Partners, Bozeman, Montana, USA.

Oyana TJ, Margai F (2015) Spatial analysis: Statistics, visualization, and computation. CRC Press, Boca Raton, Florida, USA. 
498 Palumbi SR (2001) Humans as the world's greatest evolutionary force. Science 293:1786-1790.

499 Proaktor G, Coulson T, Milner-Gulland E (2007) Evolutionary responses to harvesting in $500 \quad$ ungulates. Jour Anim Ecol 76:669-678.

501 Proffitt KM, Grigg JL, Hamlin KL, Garrott RA (2009) Contrasting effects of 502 wolves and Human Hunters on Elk Behavioral Responses to Predation Risk. $503 \quad$ J Wildl Manage 73:345-356.

504 Reby D, Charlton BD, Locatelli Y, McComb K (2010) Oestrous red deer hinds prefer male roars 505 506 with higher fundamental frequencies. Proc Roy Soc Lond B: Biological Sciences $277: 2747-2753$.

507

508

509

510

511

512

513

514

515

516 517

518 519

Ripple WJ, Newsome TM, Wolf C, Dirzo R, Everatt KT, Galetti M, Hayward MW, Kerley GIH, Levi T, Lindsey PA, Macdonald DW, Malhi Y, Painter LE, Sandom CJ,Terborgh J, Van Valkenburgh B (2015) Collapse of the world's largest herbivores. Science Advances. 2015 May 1;1(4): e1400103.

Roden C, Vervaecke H, Van Elsacker L (2005) Dominance, age and weight in American bison males (Bison bison) during non-rut in semi-natural conditions. Applied Animal Behaviour Science 92:169-177.

Ryan MJ (1985) The tungara frog: a study in sexual selection and communication. University of Chicago Press, Chicago

Semple S, McComb K (2000) Perception of female reproductive state from vocal cues in a mammal species. Proc Roy Soc Lond B: Biological Sciences 267:707-712.

Stankowich T (2008) Ungulate flight responses to human disturbance: A review and metaanalysis. Bio Cons 141:2159-2173. 
520 Theuerkauf J, Rouys S (2008) Habitat selection by ungulates in relation to predation risk

521 by wolves and humans in the Białowieza Forest, Poland. For Ecol Manage 256:1325-

$522 \quad 1332$.

523 Tilson RL, Norton PM (1981) Alarm duetting and pursuit deterrence in an African antelope. Am $524 \quad$ Nat 118:455-462.

525 Wright S, (1938) Size of population and breeding structure in relation to evolution. Science $526 \quad 87: 430-431$

527 Wyman MT, Mooring MS, McCowan B, Penedo MCT, Hart LA (2008) Amplitude of bison 528 bellows reflects male quality, physical condition and motivation. Anim Behav 76:1625$529 \quad 1639$.

530 Yarmoloy C, Bayer M, Geist V (1988) Behavior responses and reproduction of mule 531 deer, Odocoileus hemionus, does following experimental harassment with an all-terrain $532 \quad$ vehicle. Can Field Nat 102:425-429.

533 Yoshida T, Jones LE, Ellner SP, Fussmann GF, and Hairston NG (2003) Rapid 534 evolution drives ecological dynamics in a predator-prey system. Nature 424:303-306 535 doi:10.1038/nature01767. 


\section{Table 1 (on next page)}

Spearman's Rank Correlation

Spearman's correlations between bellowing rate and possible predictor variables of Plains bison in South Dakota, 1 July - 13 August, 2013. 
1

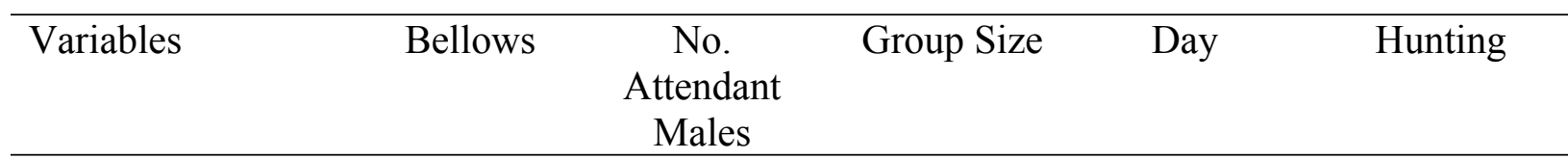

Bellows

No. Attendant Males - -.078

Group Size

$.257 * * * \quad .177 * *$

Day

$-.235 * * * \quad .573 * * *$

$-.240 * * *$

Hunting

$-.576 * * *$

$.475 * * *$

$-.218 * * *$

$.671 * * *$

No. Adult Females

$-.43$

$.442 * * *$

$.676 * * *$

.099

$.210^{* *}$

2 Note. ${ }^{*} p<.05, * * p<.01, * * * p<.001 ; d f=242$ in all cases. 


\section{Table 2 (on next page)}

Poisson Regression

Poisson regression analysis for bellowing rate of bison bulls from two hunted populations and one non-hunted population in South Dakota, from 1 July - 13 August 2013. 
1

\begin{tabular}{lccccc}
\hline \multicolumn{1}{c}{ Variable } & IRR & $\boldsymbol{S E}$ & $\boldsymbol{z}$ & $\boldsymbol{p}$ & VIF \\
\hline Day & 1.055 & 0.003 & 19.36 & $<0.001$ & 2.41 \\
No. of Attendant Males & 1.053 & 0.003 & 17.20 & $<0.001$ & 1.35 \\
No. of Adult Females & 1.004 & 0.000 & 9.39 & $<0.001$ & 1.95 \\
Group Size & 1.002 & 0.000 & 11.88 & $<0.001$ & 2.34 \\
Hunting & 0.053 & 0.003 & -58.43 & $<0.001$ & 2.28
\end{tabular}

2 Note. $N=243$, LR $\chi^{2}(5)=7085.60, p<.0001$; Pseudo $R^{2}=.5259$. Data shown are Incident Rate

3 Ratios, standard errors, $z$-statistics, $p$-values, and Variance Inflation Factors (VIF) (derived from

4 an identically specified linear regression analysis).

5

6 


\section{Table 3(on next page)}

Poisson Regression with Interaction

Poisson regression analysis of the interaction between hunting and number of attendant males on bellowing rate of bison bulls from two hunted populations and one nonhunted population in South Dakota, from 1 July - 13 August 2013. 
1 Table 3 Poisson regression analysis of the interaction between hunting and number of attendant

2 males on bellowing rate of bison bulls from two hunted populations and one non-hunted

3 population in South Dakota, from 1 July - 13 August 201.

\begin{tabular}{lccccc}
\hline \multicolumn{1}{c}{ Variables } & IRR & $\boldsymbol{S E}$ & $\boldsymbol{z}$ & $\boldsymbol{p}$ & VIF \\
\hline Constant & 1.153 & 0.095 & 1.73 & 0.083 & \\
No. of Attendant Males (Std.) & 1.614 & 0.029 & 27.07 & $<0.001$ & 1.49 \\
Day & 1.060 & 0.003 & 21.50 & $<0.001$ & 2.41 \\
\# Adult Females & 1.004 & 0.000 & 9.68 & $<0.001$ & 1.95 \\
Group Size & 1.002 & 0.000 & 11.79 & $<0.001$ & 2.39 \\
Hunting (Std.) & 0.236 & 0.006 & -57.91 & $<0.001$ & 2.30 \\
Hunting *\#Attendant males & 1.227 & 0.014 & 18.24 & $<.001$ & 1.23
\end{tabular}

$4 \overline{\text { Note. } N=243 \text {, LR } \chi^{2}(6)=7348.93, p<0.0001 \text {; Pseudo } R^{2}=0.5455 \text {. Data shown are }}$

5 Incident Rate Ratios, standard errors, $z$-statistics, $p$-values, and Variance Inflation

6 Factors (VIF) (derived from an identically specified linear regression analysis). Std. indicates

7 that variable in standardized. 
Figure 1 (on next page)

Average bellow rate of bulls

Average bellowing rate of bison bulls in groups containing fewer than and greater than the mean number of attendant males in two hunted populations and one protected population in South Dakota, from 1 July - 13 August 2013. Extending lines indicate \pm 1 standard deviation. 


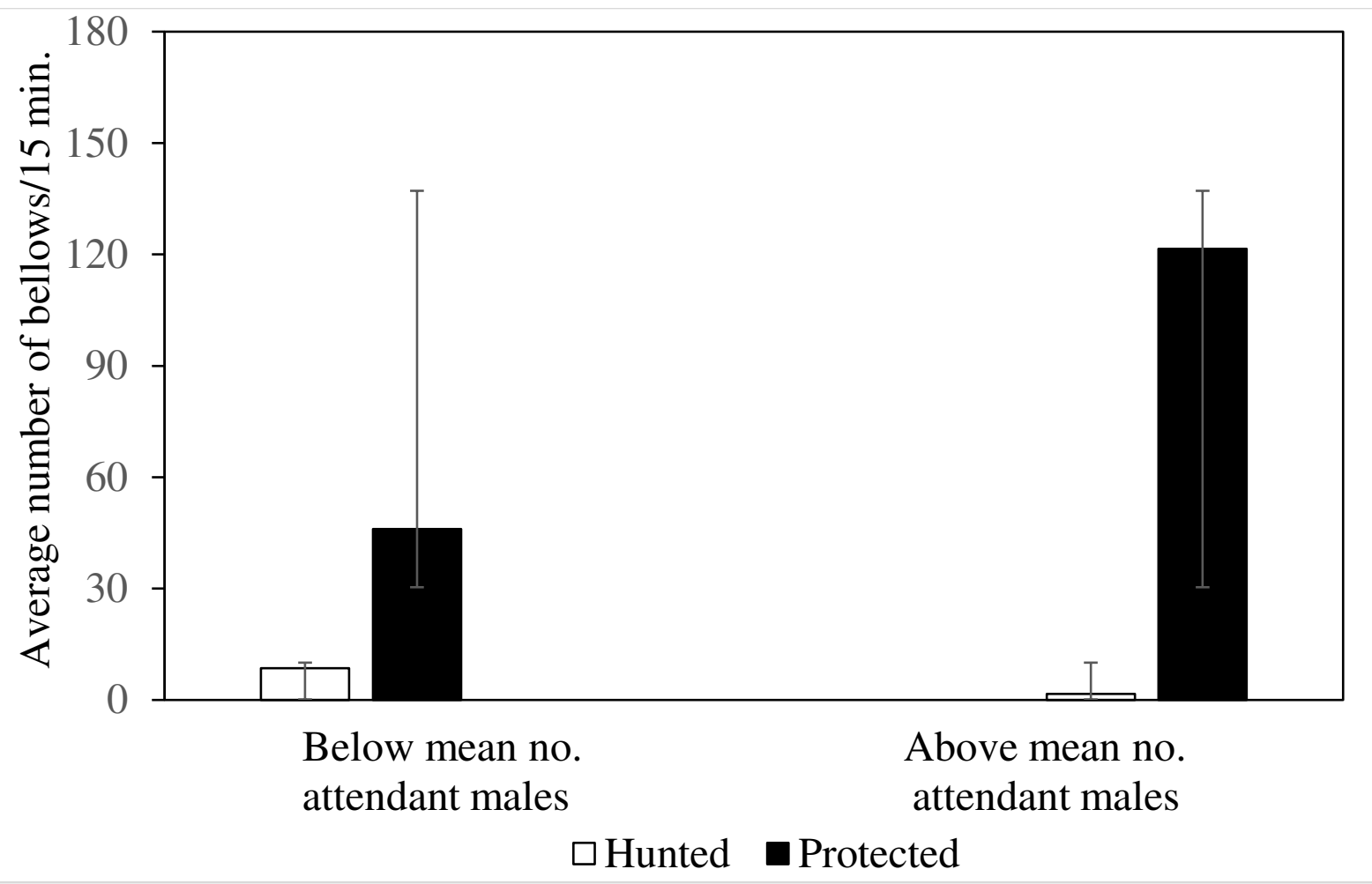

